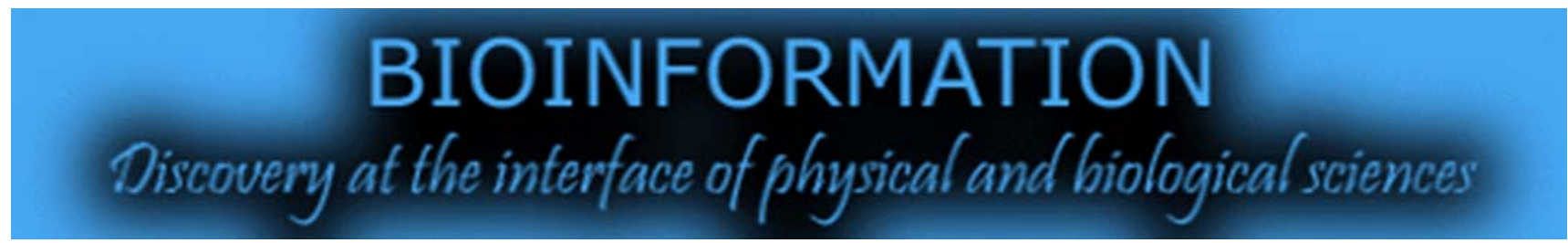

\title{
Ectomychorrizal DB: a symbiotic association database
}

\author{
Veena Pande*, Sushil Kumar Middha, Nitin Kumar Sharma, Yogesh Lohani, Mayank Pandey
}

DBT-BIF Facility, Department of Biotechnology, Kumaun University, Nainital, Uttarakhand, India; Veena Pande - Email: veena_kumaun@yahoo.co.in; *Corresponding author

Received November 15, 2011; Accepted November 16, 2011; Published January 20, 2012

\begin{abstract}
:
Ectomycorrhizal (ECM) fungal species, a "Symbiotic" relationship between tress and fungi in forest has a great ecological and economic importance. Here is an attempt to describe database named "EctomycorrhizalDB", addressing ECM diversity of Central Himalaya (Kumaun region), with special emphasis on their characterization, physical properties and morphological features along with specifications. This database would help the scientific community to draw a better understanding of the environmental factors that affects species diversity.
\end{abstract}

Availability: http://www.kubic.nic.in/ectomychorhiza

Keywords: Ectomycorrhiza, fungi, Himalayan, HTML, Pubmed, Real time, Database, MeSH, Symbiotic

\section{Background:}

Mycorrhizal symbiosis is likely to influence plant nutrition, competition and soil nutrient cycling [1]. The importance of the mycorrhizal colonization for life survival has been widely acknowledged, as $90 \%$ of plant species have an association with mycorrhizal fungi [2]. The role of mycorrhizal fungi in nutrient uptake by host plant may vary from one group of fungi to another, and with changing environmental conditions. However, it remains the least known component from the standpoint of species diversity. They are majorly classified into various categories like endo, ecto, ectoendomychorrhiza etc. Ectomycorrhizal (ECM) fungi accounts for $25 \%$ or more of the root mass of forest plants such as pine (Pinus), spruce (Picea), fir (Abies), poplar (Populus), willow (Salix), beech (Fagus), birch (Betula), dipterocarp, eucalyptus, oak (Quarcus) and rose families [3, 4]. So, it is representing a major underneath structural component of the forest ecosystem. The Central Himalaya (Kumaun region) shows rich diversity in Oak and Pine trees, accounting ECM association more than 50\% [5].The importance of ECM fungi in determining plant diversity relative to other mechanisms such as species competition and species coexistence has been studied extensively [6]. Since ECM is considered to be a multipurpose net having about 500 documented uses $[7,8]$, its importance has been increased many folds in the last few decades. There are distinct assemblages of some new unknown ECM species associated with Gymnosperms/ Angiosperms first time in Central Himalaya in comparison with other species, making the formation of common mycorrhizal networks (CMNs) between them unlikely $[3,9]$. This academic database is first of its kind available in a public domain worldwide. Considering the ecological and economical significance of ECM in Kumaun region, authors are making first effort to explore this region with the consultation of a taxonomist. The primary goal of this database is to extensively address the published literature on ECM taxonomy, edible properties, morphological features etc. ECMdb is an attempt to give compiled information on various species of mychorrhizae encountered in the same. 


\section{Methodology:}

DATABASE:

A relationally organized database was designed to serve as a repository of species with Ectomycorrhizal identity. The database was implemented using MySQL (http://www.mysql.com), a free-to-use RDBMS while the scripts were written in HTML. Linux web server was used to deliver the interface.

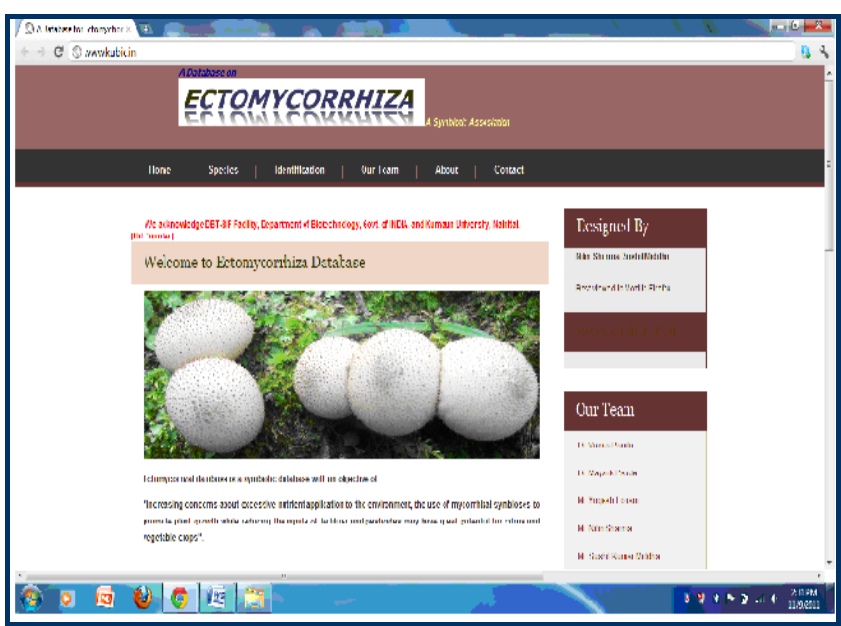

Figure 1: a snap shot of ectomycchorizal database

\section{Database construction}

The methodology followed in constructing ECMdb is as per Middha et al., 2009 [10].

\section{Data collection}

Initially an extensive fieldwork was done to collect ECM fungi associated with oak and pine trees. After getting the samples from the field, identifications were made by examining various macroscopic, microscopic, and chemical characteristic as per our previous studies [4]. A search with MeSh terms "Ectomycorrhiza" and "Central Himalaya" or "Kumaun Region" was carried out on all literature databases available such as PubMed [11], ScienceDirect [12], Mary Ann Liebert [13], BlackWell Synergy [14], Scirus [15], Bentham Publishers [16], BioMedAsia [17], Indian Journals [18] and others. This resulted in an initial list of 102. In order to remove cross-database (Xref) redundancy, searches were repeated with the same keyword through the internet, local agencies, researchers, local people through a questionnaires and results downloaded onto local machines. Unless otherwise explicitly stated, all further processing was carried out locally using default parameters.

The final lists of 79 species obtained at this stage were manually scrutinized and scientifically proved 51 species were retained in the database, based on their primary annotations. For every entry, vital information pertaining to the species name, morphological characterization, and their real time pictures, structure, source, were included.

\section{Curation of data}

All ECM species identifications, abstracts, titles, and articles were reviewed by two experts, and all divergences were resolved by consensus. We have tabulated all the mycorrhizal genera and species found in the Central Himalaya, particularly
Kumaun region, with their specific host species by conducting an extensive search of contents of the published papers related to macro fungi of the area. ECM pictures exhibited in this database had been clicked by one of the authors and are real time. The major genera in terms of species were Amanita (7 sp.), Russula (4 sp.), Boletus (6 sp.), Lactarius (5 sp.), Hygrophorus (1 sp.) and Cortinarius (2 sp.).

\section{Results:}

The ECMDdb, thus created using the above mentioned methodology, contains a total number of 51 Ectomycorrhizal species of Kumaun region. The outlook of ECMdb is as illustrated in (Figure 1).

\section{Discussion:}

ECMdb provides an easy-to-use web interface with flexibility to select for an entry or a collective set of entries matching user's criteria such as name of the species, morphological features. Empirical evidence of efficacy of this database for mychorriza would be helpful to identify areas for potential research in future to provide a rapid review on numerous mychorrhizal species for the benefit of the scientific community.

\section{Future development:}

$\mathrm{ECM} \mathrm{db}$ is the first approach as a free accessible academic real time database for ECM species found in Kumaun region. We are going to incorporate more scientific information regarding mychorrhizal species of this region as well as worldwide. Periodically continuous updates shall be unconfined to embrace other mychorrhizal species. We plan to incorporate a provision to avail the required information using keywords.

\section{Acknowledgments:}

This research has been carried out in Kumaun University, DBTBIF facility under BTIS (Biotechnology information system), DBT (Department of biotechnology), Ministry of Science and Technology, Government of India, India. The authors are also grateful to whole scientific community for their contribution towards science.

\section{CONFLICT OF INTEREST}

The authors have no conflicts of interest to declare.

\section{Referrences:}

[1] Karkouri El et al. Microbiol Res. 2005 160: 47 (2005) (PMC 15782937)

[2] Pande V et al. curr Sci. 2007 92: 80

[3] Wang B \& Qiu YL, Mycorrhiza. 2006 16: 299 (PMID: 16845554

[4] Pande V et al. Curr Sci. 2004 86: 1619

[5] Reinhardt D, Curr Opin Plant Biol. 2007 10: 98 (PMC 1712709).

[6] CJET Yu et al. Mycorrhiza 2001 11: 167

[7] Eastwood DC et al. Science. 2011 333: 762 (PMID 21764756)

[8] Rosling A et al. Science. 2011 333: 876

[9] Bent E et al. Applied and Environmental Microbiol. 2011 3351: 9

[10] SK Middha et al. Bioinformation, 2009 4: 78 [PMC2823386]

[11] http://www.ncbi.nlm.nih.gov

[12] http://www.sciencedirect.com

[13] http://www.liebertpub.com

[14] http://www.blackwellsynergy 
[15] http://www.scirus.com/srsapp/

[16] http://www.bentham.org
[17] www.bma.org.in

[18] www.indianjournals.com

Edited by P Kangueane

Citation: Pande et al. Bioinformation 8(2): 104-106 (2012)

License statement: This is an open-access article, which permits unrestricted use, distribution, and reproduction in any medium, for non-commercial purposes, provided the original author and source are credited. 